\title{
The sexual lives of breast cancer patients: Coping with changes associated with treatment
}

\author{
Ayumi Yoshikawa*1, Shinya Saito ${ }^{1}$, Makiko Kondo ${ }^{1}$, Yuko Tsuyumu ${ }^{2}$, Naruto Taira ${ }^{3}$, Tadahiko Shien ${ }^{3}$, Hiroyoshi \\ Doihara $^{3}$ \\ ${ }^{1}$ Graduate School of Health Sciences, Okayama University, Japan \\ ${ }^{2}$ Nursing Department, Okayama University Hospital, Japan \\ ${ }^{3}$ Department of Breast and Endocrine Surgery, Okayama University Hospital, Japan
}

Received: August 29, 2017

DOI: $10.5430 /$ cns.v6n1p61
Accepted: November 16, $2017 \quad$ Online Published: November 24, 2017

URL: https://doi.org/10.5430/cns.v6n1p61

\begin{abstract}
Objective: To clarify how breast cancer patients undergoing post-surgical hormone therapy cope with changes in their sexual lives and support themselves and their partners during these changes.

Methods: Participants were 37 breast cancer patients undergoing post-surgical hormone therapy and attending mammary outpatient clinics. In-depth interviews and grounded theory were used to collect and analyze data, respectively.

Results: First, sexual life was divided into four groups: "No complaint" regarding sexual activity, "Slight discord", "Handicapped in meeting a life partner" and "Uninterested" in sexual activity. Sexual life during surgical-hormone therapy did not change significantly from sexual life before breast cancer. Second, meanings of sexual activity for breast cancer patients were divided into five, "Regaining femininity", "Confirming love", "Sharing pleasure", "Response to partner's higher desire" and "Procreation". They differed by group. Third, coping strategies were divided into six, "Virtuous cycle to confirm love and regain lost femininity", "Struggle to avoid relationship crisis", "Reconfirmation of partner's affection by his abstinence", "Attempt to recover the sexual activity they hope for", "Pursuing children or assuaging partner's desire by other means" and "Difficulty making a partner continue to have sexual activity".

Conclusions: Nurses should screen breast cancer patients for changes in their sexual lives and to ascertain what sexual activity means to patients, and support them in selecting appropriate coping methods.
\end{abstract}

Key Words: Sexual life, Sexuality, Breast cancer, Coping, Grounded theory

\section{INTRODUCTION}

Sexuality is very important to humans, and encompasses much more than sexual function. ${ }^{[1]}$ Sexuality influences our self-perceptions, as well as our perceptions of our bodies and sexual relationships. ${ }^{[1]}$ It is a fundamental and important element of the constantly changing human experience. ${ }^{[1]}$ Sexuality involves sex, gender identity, roles, pleasure, inti- macy, and reproduction. ${ }^{[2]}$ It is strongly influenced by social, cultural, and historical factors. ${ }^{[1-3]}$

Cancers that are strongly related to feminine identity can affect sexual experience. In particular, uterine cancer affects sexual intercourse. ${ }^{[4]}$ Support for the sexual lives of cancer patients is important. Meanwhile, the incidence of breast cancer is higher than that of uterine cancer. ${ }^{[5]}$ Breasts are Japan.

Published by Sciedu Press 
commonly held to be a symbol of femininity, ${ }^{[6]}$ and as such, changes to the patient's body image caused by surgery can affect their sexuality and sexual life. ${ }^{[7-9]}$ The incidence of breast cancer is high among young women, and breast cancer treatments can affect fertility. ${ }^{[10]}$

Major breast cancer treatments include breast-conserving surgeries (lumpectomy, quadrantectomy, partial mastectomy, and segmental mastectomy), chemotherapy, radiation therapy, and hormone therapy. About $70 \%$ of breast cancer is estrogen receptor positive. ${ }^{[11]}$ Hormone therapies involving LH-RH agonists, estrogen receptor inhibitors, and aromatase inhibitors are effective adjuvant treatments for breast cancer. $^{[9]}$ Research on breast cancer treatment indicates the need to continue hormone therapy for 5 years or more. ${ }^{[12]}$ Breast cancer patients may experience some side effects as a result of long-term hormone therapy, such as menopausal disorder, vaginal dryness, and dyspareunia, ${ }^{[6,7,12,13]}$ all of which can affect sexual life. Hormone therapy and breastconserving surgery can both impact a patient's sexuality and sexual experiences.

According to previous studies, the sexual lives and sexualities of breast cancer patients can be divided into three categories: sexual dysfunction, sexual-wellbeing, and sexual relationships with partners. First, some studies report that breast cancer patients experience sexual dysfunction and changes in body image as a result of the treatment, ${ }^{[9,14,15]}$ and that these changes and dysfunction reduce the frequency of sexual activity in breast cancer patients ${ }^{[13,16]}$ as well as sexual satisfaction and the ability to achieve orgasm. ${ }^{[9]}$ These previous studies have also shown that breast cancer patients experience anxiety and problems in their sex lives. Second, several studies found that breast cancer patients have difficulty in attaining sexual well-being. ${ }^{[6,17]}$ Beckjord and Compas reported that a decline in sexual quality was related to a decline in the overall quality of life (QoL) of breast cancer patients. ${ }^{[18]}$ Third, the studies report that reduction in sexual activity affected marital relationships, and breast cancer patients experienced anxiety about their relationship with a partner due to sexual activity decrease. ${ }^{[6,16,17]}$ Fang, Lin, Chen, and Lin additionally reported that decreases in sexual activity were related to an overall deterioration in communication between couples. ${ }^{[19]}$ Therefore, previous studies have demonstrated that couples coping with declining sexual relationships are important for maintaining sexual relations.

While many studies have examined sexuality in breast cancer patients, only a few have investigated the practical implications in clinical settings. Surgery and hormone therapy are associated with sexual life and sexuality, and breast cancer patients continue to live their daily lives along with receiving hormone therapy; therefore, it is necessary to provide support to patients by targeting their sex lives and sexuality.

Nurses are professionals who provide support to patients; therefore, they must intervene in patients' sexual life and sexuality. ${ }^{[1,20]}$ However, in every country, medical staff face difficulties intervening in patients' sexual lives and sexuality, either due to a lack of knowledge or avoidance of sexuality. ${ }^{[1,6,20-22]}$ For their part, patients do not feel comfortable consulting medical professionals about their problems, and this aversion prevents them from obtaining the necessary information. ${ }^{[6]}$ However, sexuality is related to QoL, and as such, medical providers need to intervene in sexual issues to improve the QoL of patients. ${ }^{[6,22]}$

\subsection{Concept of sexual life}

"Sex refers to the biological characteristics that define humans as female or male." ${ }^{2]}$ Sexual activity includes sexual intercourse. ${ }^{[6]}$ Additionally, "Sexuality is a central aspect of being human throughout life and encompasses sex, gender identities and roles, sexual orientation, eroticism, pleasure, intimacy, and reproduction"; [2] "it is influenced by the interaction of biological, psychological, social, economic, political, cultural, ethical, legal, historical, religious, and spiritual factors". [2] "Sexual health is a state of physical, emotional, mental, and social well-being in relation to sexuality; it is not merely the absence of disease, dysfunction, or infirmity."[2] "Sexual health requires a positive and respectful approach to sexuality and sexual relationships, as well as the possibility of having pleasurable and safe sexual experiences, free of coercion, discrimination, and violence."[2] "Sexual well-being is central to psychological well-being and QoL."[20] "Sexual QoL is broadly defined to include feelings of sexual attractiveness, interest, and participation in sexual activity, and experience of sexual function."[18] "Sexual rights embrace human rights that are already recognized in national laws, international human rights documents, and other consensus statements."[2] "Sexual life is affected by psychological and physical relationships, intimacy, body image, and sexual function."[23] It is an important factor in determining the satisfaction and stability of families. ${ }^{[24]}$

In this research, sexual life is defined as encompassing sex, gender identity, gender roles, eroticism, pleasure, intimacy, and reproduction, and is a part of the daily life of humans.

\subsection{Objectives}

- To clarify changes in the sexual lives of breast cancer patients undergoing post-surgery hormone therapy, and to understand the strategies they use to cope with these changes.

- To gain insights into how to support breast cancer pa- 
tients and their partners experiencing changes in sexual life.

\section{MeTHODS}

\subsection{Design}

This research adopted a grounded theory approach (GTA) based on the work of Corbin and Strauss ${ }^{[25-27]}$ and involved in-depth interviews with participants. The core features of GTA are continued comparative analysis and theoretical sampling. Theoretical construction is improved by using continued comparative analysis and theoretical sampling suitably.

The GTA generally consists of collecting and analyzing data in parallel. In this study, two points of GTA were altered. First, data collection preceded the analysis. The first reason for this was that it is a burden on the research participants and medical staff to perform complicated theoretical sampling in the clinical setting. The second reason was that Corbin reported the possibility of performing theoretical sampling and determining the direction of the analysis using previously collected data. The second change involved minimizing the target narrowing down to allow continued comparative analysis and theoretical sampling.

\subsection{Interview guide}

To develop an interview guide for this study, we reviewed previous research and extracted related items, with corrections and additions based on the opinions of breast cancer specialists and a certified breast cancer nurse. The final interview guide included two categories: questions about the daily lives of breast cancer patients and questions about sexual life. There were six questions concerning daily life: thoughts at the time of diagnosis, manifestation of symptoms due to surgery and treatment, changes in everyday life, changes in family relationships, changes in couple's relationships, and impact on work. The five questions regarding sexual life cover changes in sexual life, changes in the relationship with the partner, coping with sexual life changes, thoughts and feelings of embarrassment on resuming sexual life, and thoughts on having children.

\subsection{Participants}

The participants in this study were 37 female breast cancer patients who visited a mammary out-patient clinic at the cooperating hospital during data collection. Interviews were carried out between April and July 2013 at convenient times decided by the clinic staff. The inclusion criteria for this study were the following: having a diagnosis of breast cancer and an understanding of the condition and prognosis, having undergone breast-conserving surgery, and receiving hormone therapy at the time of interview. The exclusion criteria were Published by Sciedu Press the following: judged by a doctor or nurse to be psychologically unable to participate in an interview about sexual matters and having stage IV or life-threatening cancer.

\section{Ethical considerations}

This research was approved by the ethical review committee of the graduate school of health sciences at the authors' institution (August 23, 2013). The purpose and methods of the study were explained to all participants. Participants were also informed about their right to withdraw from the study at any time without facing any consequence, and were ensured that their personal information would be protected and results anonymized. Participants were further informed verbally and in writing how the data would be collected (including that an audio-recorder would be used, for which participants' permission was asked) and stored and when they would be destroyed, and that their data would only be used for the purposes of this study.

\subsection{Procedure}

In-depth interviews were conducted with participants in a counseling room at a mammary out-patient clinic while they were waiting to be examined. The interviewer (the first author) attempted to make participants feel at ease while talking by nodding in acknowledgment when the participants spoke, repeating what they said, sympathizing, and giving positive verbal backchannels. If the participants said something that was unclear, the interviewer asked them to clarify. As questions about sexual life could be sensitive, the interviewer began the interview by asking general questions about daily life before proceeding to ask questions about sexual matters. The interviewer attempted to establish a friendly rapport with the participants so that they felt more at ease and able to answer the questions. Interviews were recorded on an SONY integrated circuit recorder (ICD-UX513F) with the permission of participants. All interviews were transcribed verbatim. The average time of interviews was 29.9 minutes (range 11-63).

\subsection{Analysis}

The analysis was carried out in 3 stages. The first stage involved generating an overview of all data and developing a plan for subsequent analysis based on the overview. The second stage involved classifying the participants into groups and analyzing group data. The third stage involved comparing the results from participant groups and integrating them. Additionally, this stage attempted to refine the integration of analysis and theory. The first author underwent about 3 months' training in the mammary-outpatient clinic to better understand its functioning and the patient's situation. The analysis and results were regularly supervised by researchers 
specializing in qualitative research to ensure accuracy and validity. ${ }^{[27]}$ Each stage in the analytic process is detailed below.

\subsubsection{Analytic process (see Figure 1 and Table 1)}

Stage 1: The aim of the first phase was to acquire a general understanding of patients' sexual activity from the interviews of all 37 breast cancer patients undergoing post-surgery hormone therapy and deciding on a direction for constant comparative analysis. To do this, all interviews were transcribed verbatim and all data were sliced into individual meaningunits. Data slices were then organized into groups of similar meaning and content; the level of abstraction was increased, and the data were encoded along a timeline from prior to breast cancer diagnosis, through the period of breast cancer diagnosis, to after breast cancer. Differences in changes in sexual activity were used to split participants into three groups: A) patients who experienced a decline in sexual activity (including no sexual activity) $(n=24), B)$ patients who had resumed sexual activity $(n=6)$, and $C)$ patients without sexual partners $(n=7)$. These groups were analyzed independently, with group A being analyzed in Stage 2-1, group B being analyzed in Stage 2-2, and group C being analyzed in Stage 2-3.

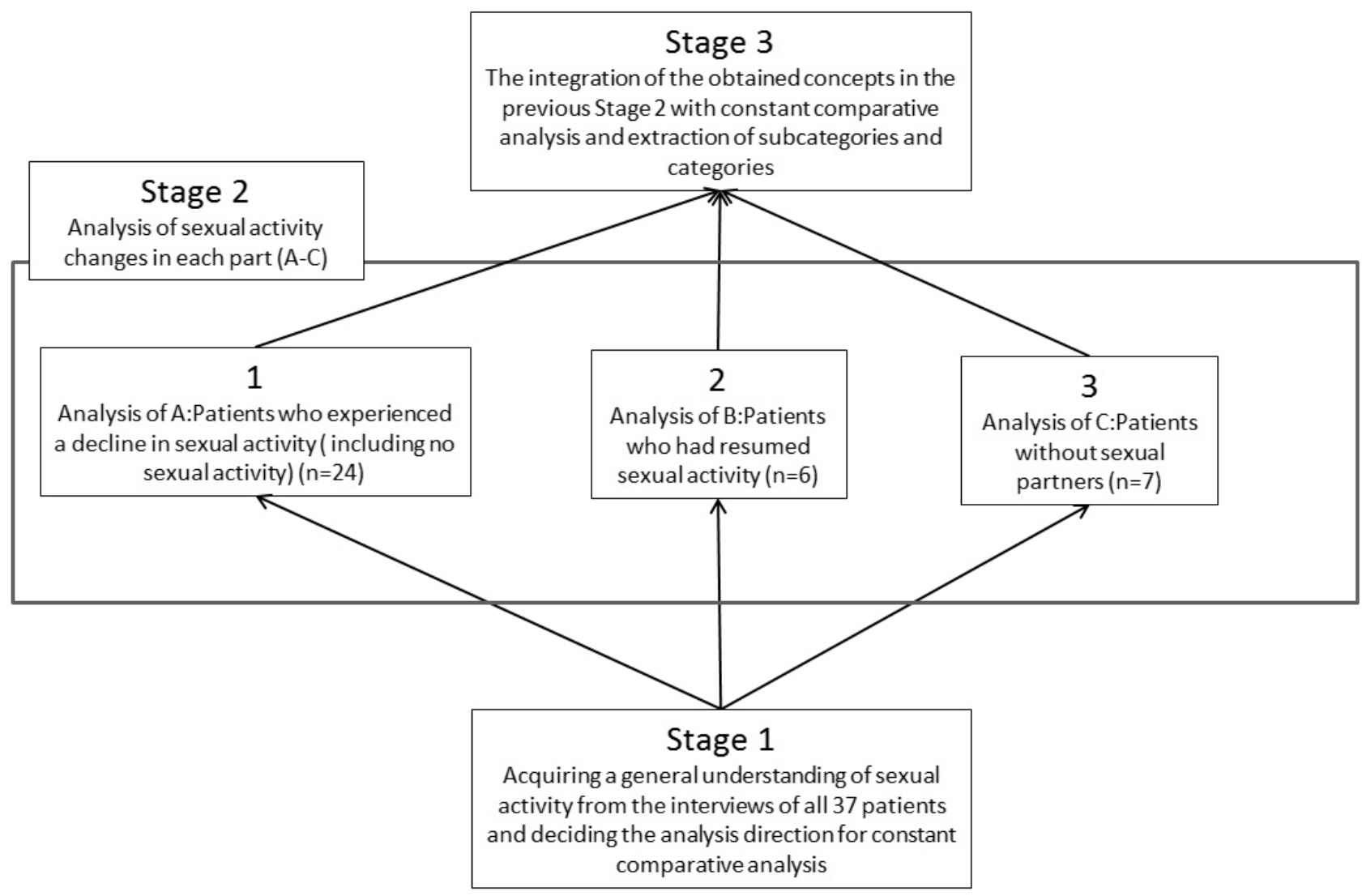

Figure 1. Analytic process

Stage 2-1: The second stage involved the analysis of sexual activity changes in group A $(n=24)$, which was the largest group included in the study. Open coding was employed to analyze the data for this group. Open coding involves selecting all data, assigning labels that accurately reflect the meaning of the data, grouping data with similar meanings, and characterizing the groups on the basis of their properties and dimensions. The sectioned data were organized by similar semantic content, and then divided into groups. Moreover, the grouped data were conceptualized and grouped according to similar meanings. ${ }^{[25,26]}$ The analysis then focused on the change in couples' sexual activities before breast cancer, breast cancer diagnosis, and after breast cancer, the details of sexual activity before breast cancer, the change in sexual activity between the couples, and coping with the change in sexual activity. The data were then schematized and mini-axial coding was performed to associate concepts and identify those with a high level of abstraction.

Stages 2-2 and 2-3: During these stages, the methodology used in Stage 2-1 was applied to investigate the sexual activity of participants in groups $B(n=6)$ and $C(n=7)$. 
Stage 3: The third stage of analysis involved the comparison and integration of data obtained in Stage 2, and the extraction of subcategories and categories. Axial coding was used to associate the concepts obtained through mini-axial coding in Stage 2. This was done from the point of properties and dimensions by increasing the abstraction of concepts through integrating concepts with the same meaning and excluding concepts with different meaning. Moreover, axially coded data during this stage were compared with, organized in terms of, and integrated with each concept. Selective coding was applied to grasp more phenomena with a higher degree of abstraction. ${ }^{[25-27]}$ The researchers developed a figure including the analysis of results and all ideas previously written down as notes. It was repeatedly checked and corrected until it contained all data, with concepts categorized by semantic relatedness and abstraction level. Additionally, subcategories and categories were extracted. The final figure was composed of four parts: I. Sexual activity before breast cancer, II. Changes in sexual activity caused by breast cancer and factors causing the change in sexual activity, III. What sexual activity means to breast cancer patients, and IV. Strategies used to cope with changes in sexual activity.

Table 1. Analytic process

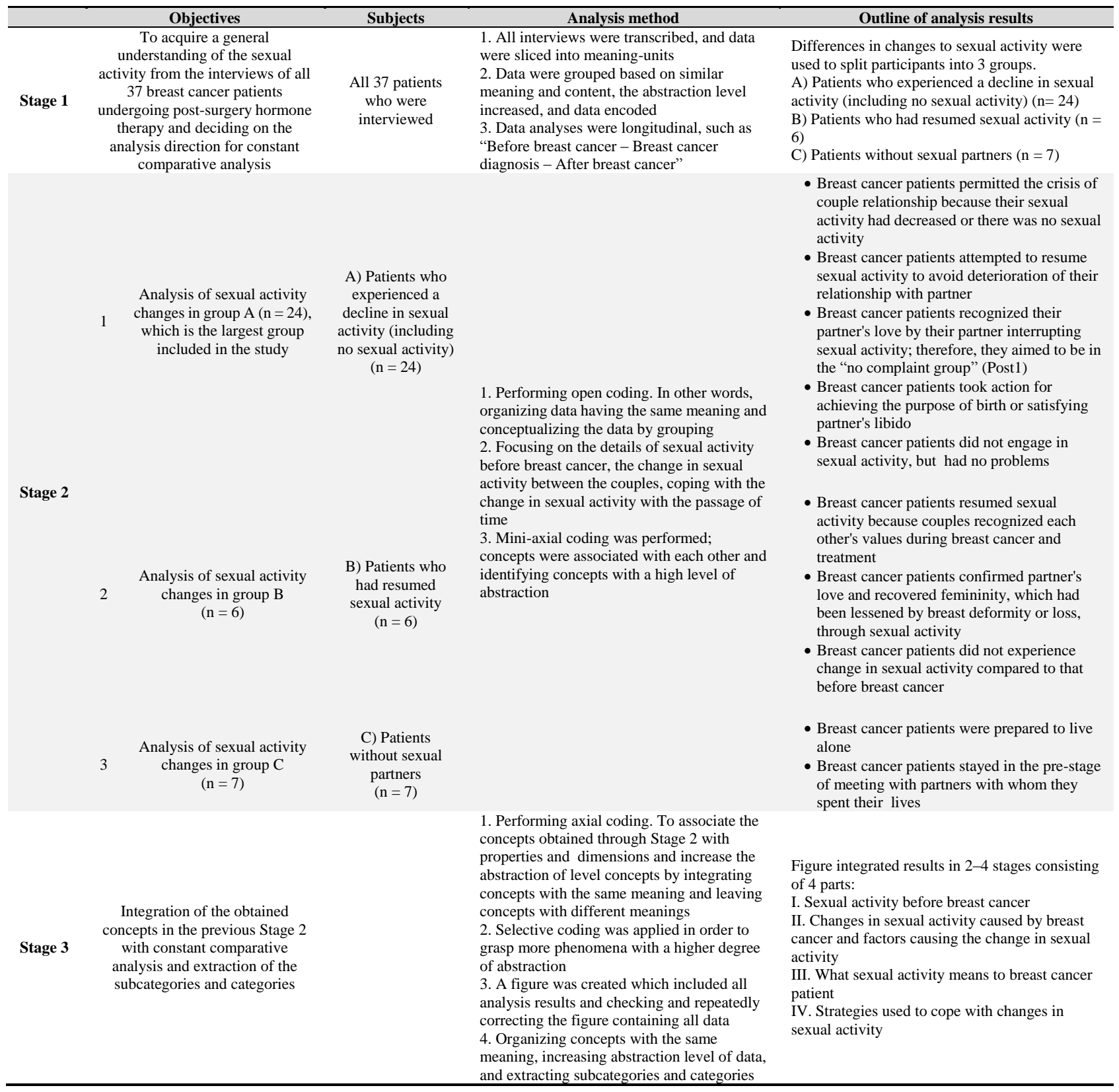




\section{Results}

The results consist of 4 parts (see I-IV in Figure 2), along with data on participant characteristics. First, we describe the research participants.

\subsection{Participant characteristics (see Table 2)}

The participants were 37 women with a breast cancer diagnosis who were undergoing post-surgery hormone therapy, and who attended a mammary outpatient clinic during the research period. The mean age of participants was $46.3 \pm 12.7$ years. The majority of the participants $(\mathrm{n}=30)$ had a partner, 26 had children, and 6 were already menopausal. Fourteen participants had undergone mastectomy, 23 had undergone breast-conserving surgery, 9 had received an axillary lymphadenectomy, and 4 patients had received breast reconstruction. Three patients had received only chemotherapy, 18 only radiation therapy, 8 patients a combination of chemotherapy and radiation therapy, and 8 patients had received neither. The mean duration from the time of surgery to the time of interview was $18.9 \pm 10.9$ months. While 35 participants agreed to their interviews being recorded, 2 declined, resulting in their interviews being transcribed. Participant characteristics are displayed in Table 2.
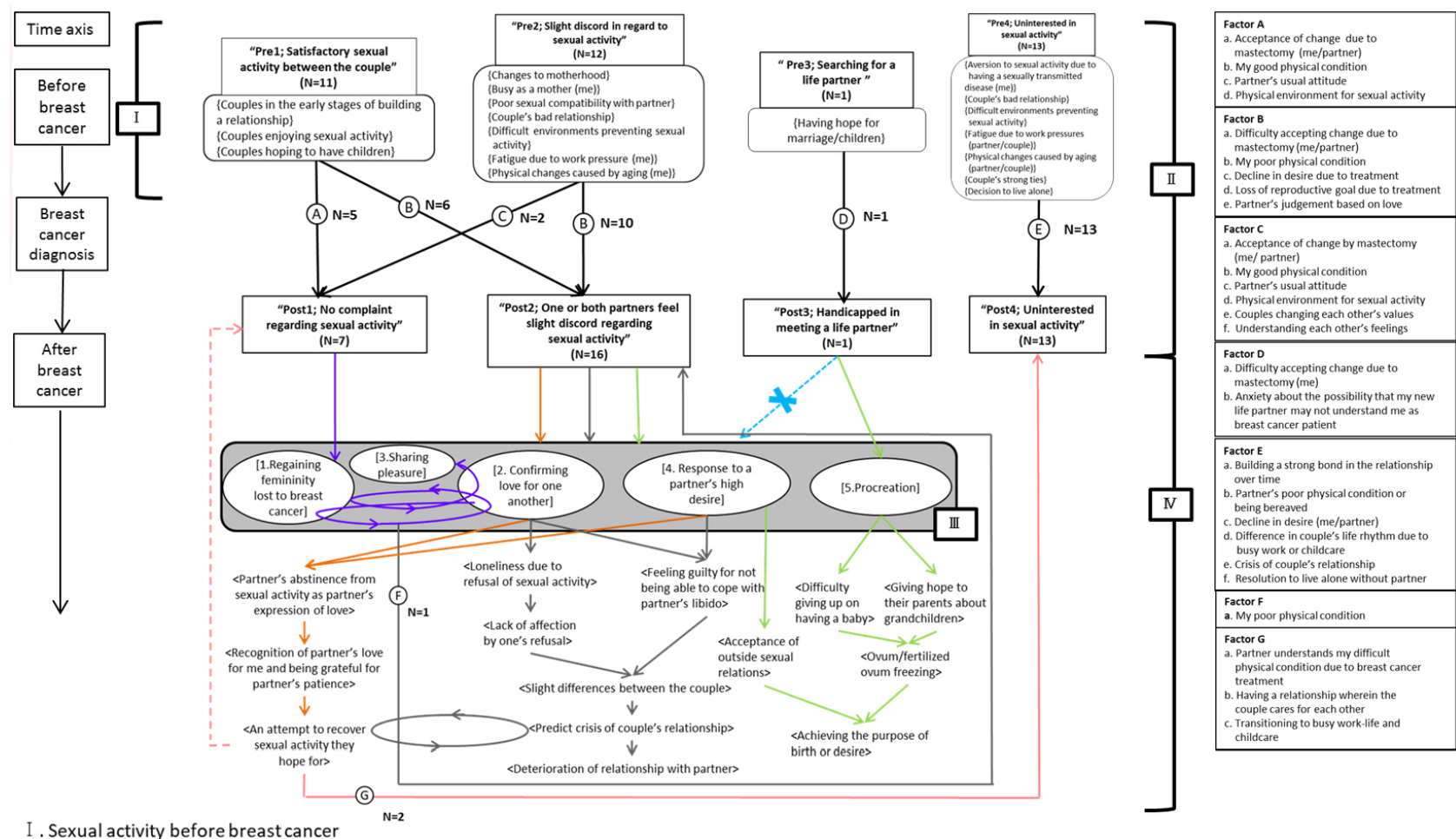

I . Sexual activity before breast cancer

II. Changes in sexual activity caused by breast cancer A-E factors: Factors causing the change in sexual activity

III. What sexual activity means to breast cancer patients

N. Strategies used to cope with changes in sexual activity

1. $\rightarrow$ : Virtuous cycle to confirm couple's love and regain lost femininity through sexual activity

$2 . \rightarrow$ : Struggle to avoid relationship crisis related to disruption of sexual activities

3. $\rightarrow$ : Reconfirmation of partner's affection by his abstinence from sexual activity

4. $\rightarrow$ : Attempt to recover the sexual activity they hope for

5. $\rightarrow$ : Pursuing children or assuaging partner's desire by other means

6. $\rightarrow$ : Difficulty making a partner continue to have sexual activity

Figure 2. Changes and coping in sexual lives associated with treatment of breast cancer patient

\subsection{Outline of sexual activity for breast cancer patients}

A full picture of the sexual life of these breast cancer patients is shown in Figure 2. Figure 2-I shows the sexual activity of breast cancer patients before breast cancer, dividing them into 4 groups. Figure 2-II shows how sexual activity changed due to breast cancer. As the black arrows indicate, sexual lives during surgical-hormonal therapy were divided into 4 groups, which were similar to the groups for sexual activity prior to breast cancer. Participants' transition from the earlier to the later groups occurred by combinations of Factors A-E. In Table 3, the definition of the factors is shown. In Figure 2-III and Table 4, we see that the meaning of sexual activity during treatment varied by group. Figure 2-IV shows how the groups coped with change in sexual activity during surgical 
hormonal therapy, with six coping strategies shown, respectively in purple, gray, orange, pink, yellow-green, and light blue arrows. In what follows, the group names are placed in double quotation marks, " ", changes in their sexual activity inside braces, \{\} , factors influencing those changes in single quotes, ' ', meanings of sexual activity in square brackets, [ ], coping strategies in double pointy brackets, «», and the processes involved in these strategies in single pointy brackets, $<>$.

Table 2. Research participants

\begin{tabular}{|c|c|c|}
\hline \multicolumn{2}{|l|}{ Basic attributes } & $\begin{array}{l}\text { Research participants } \\
(\mathbf{N}=37)\end{array}$ \\
\hline \multicolumn{2}{|l|}{ Age (years) } & $46.3 \pm 12.7(24-69)$ \\
\hline \multirow{4}{*}{ Stage } & $\bullet 0$ (DCIS) & 7 \\
\hline & - I & 22 \\
\hline & • II & 7 \\
\hline & $\bullet$ III & 1 \\
\hline \multirow{4}{*}{$\begin{array}{l}\text { Type of } \\
\text { surgery }\end{array}$} & - Mastectomy & 14 \\
\hline & - Breast conserving surgery & 23 \\
\hline & - Axillary lymphadenectomy & 9 \\
\hline & - Breast reconstruction & 4 \\
\hline \multirow{3}{*}{ Chemotherapy } & $\circ$ Pre-surgery & 3 \\
\hline & - Yes $\quad$ Post-surgery & 7 \\
\hline & • No & 27 \\
\hline \multirow{2}{*}{ Radiotherapy } & - Yes & 26 \\
\hline & $\bullet$ No & 11 \\
\hline \multirow{4}{*}{ Marital status } & - Married & 26 \\
\hline & - Divorced/Separated & 4 \\
\hline & - Bereaved & 3 \\
\hline & - Single & 4 \\
\hline \multirow{2}{*}{ Partner } & - Yes & 30 \\
\hline & $\bullet$ No & 7 \\
\hline \multirow{2}{*}{ Children } & - Yes & 26 \\
\hline & • No & 11 \\
\hline \multirow{2}{*}{ Menopause } & - Yes & 6 \\
\hline & $\bullet$ No & 31 \\
\hline \multicolumn{2}{|c|}{ Term from surgery to interview (months) } & $18.9 \pm 10.9(4-53)$ \\
\hline
\end{tabular}

\subsubsection{Sexual activity before breast cancer diagnosis (see Figure 2-I)}

The sexual activity of breast cancer patients prior to diagnosis was divided into four situations: "Pre1: Satisfactory sexual activity between the couple", "Pre2: Slight discord in regard to sexual activity", "Pre3: Searching for a life partner" and "Pre4: Uninterested in sexual activity" (see Figure 2-I). Pre1 contained the themes of \{Couples in the early stages of building a relationship\}, \{Couples enjoying sexual activity\}, and $\{$ Couples hoping to have children $\}$. Pre 2 contained the themes of $\{$ Changes to motherhood $\}$, \{Busy as a mother (me) $\},\{$ Poor sexual compatibility with partner $\}$, \{Couple's bad relationship $\},\{$ Difficult environments preventing sexual activity $\},\{$ Fatigue due to work pressure (me) $\}$, and $\{$ Physical changes caused by aging (me) $\}$. Pre 3 contained the theme of $\{$ Having hope for marriage/children $\}$. Pre 4 contained the themes of \{Aversion to sexual activity due to having a sexually transmitted disease (me) $\}$, \{Couple's bad relationship\},
\{Difficult environments preventing sexual activity $\},\{$ Fatigue due to work pressures (partner/couple) $\},\{$ Physical changes caused by aging (partner/couple)\}. \{Couple's strong ties $\}$, and $\{$ Decision to live alone. $\}$

\subsubsection{Changes in sexual activity caused by breast cancer and associated factors (see Figure 2-II and Table 3)}

Sexual activity during post-surgical hormone therapy (Figure 2-II): Sexual activity during post-surgical hormone therapy was divided into four situations: "Post1: No complaint regarding sexual activity", "Post2: One or both partners feel slight discord regarding sexual activity", "Post3: Handicapped in meeting a life partner" and "Post4: Uninterested in sexual activity."

Changes in sexual activity caused by breast cancer and determining factors (Figure 2-II, Table 3): The nature of the changes in sexual activity caused by breast cancer were determined by multiple factors, as shown in Figure 2-II. The definition of each factor is shown in Table 3. "Pre1: Satisfactory sexual activity between the couple" transitioned to "Post1: No complaint regarding sexual activity" by factor A, consisting of 'a. Acceptance of change due to mastectomy (me/partner)', 'b. My good physical condition', 'c. Partner's usual attitude' and 'd. Physical environment for sexual activity' and to "Post2: One or both partners feel slight discord regarding sexual activity" by factor B, consisting of 'a. Difficulty accepting change due to mastectomy (me/partner)', 'b. My poor physical condition', 'c. Decline in desire due to treatment', 'd. Loss of reproductive goal due to treatment' and 'e. Partner's judgment based on love'. "Pre2: Slight discord in regard to sexual activity" transitioned to Post 2 by factor B and to Post1 by factor C. "Pre3: Searching for a life partner" transitioned to "Post3: Handicapped in meeting a life partner" by factor D. "Pre4: Uninterested in sexual activity" transitioned to "Post4: Uninterested in sexual activity" by factor $\mathrm{E}$.

\subsubsection{Differences in the meaning of sexual activity be- tween groups (Post1-4) after changes in sexual ac- tivity (see Figure 2-III and Table 4)}

As shown in Figure 2-III, the meanings patients attached to sexual activity were divided into 5 types: [1. Regaining femininity lost to breast cancer], [2. Confirming love for one another], [3. Sharing pleasure], [4. Response to a partner's high desire], and [5. Procreation]. The meaning of sexual activity thus appears different by post-group, as follows.

Regaining femininity lost to breast cancer (Table 4): "Post1: No complaint" regained their sense of self, while "Post2: Slight discord" felt that they were not seen as women by their partners, or there was no need for [1. Regaining femininity lost to breast cancer]. "Post3: Handicapped in 
meeting life partner" could not think about regaining their not appear interested in regaining femininity and did not femininity, and "Post4: Uninterested in sexual activity" did think of it as important.

Table 3. Definition of the factors

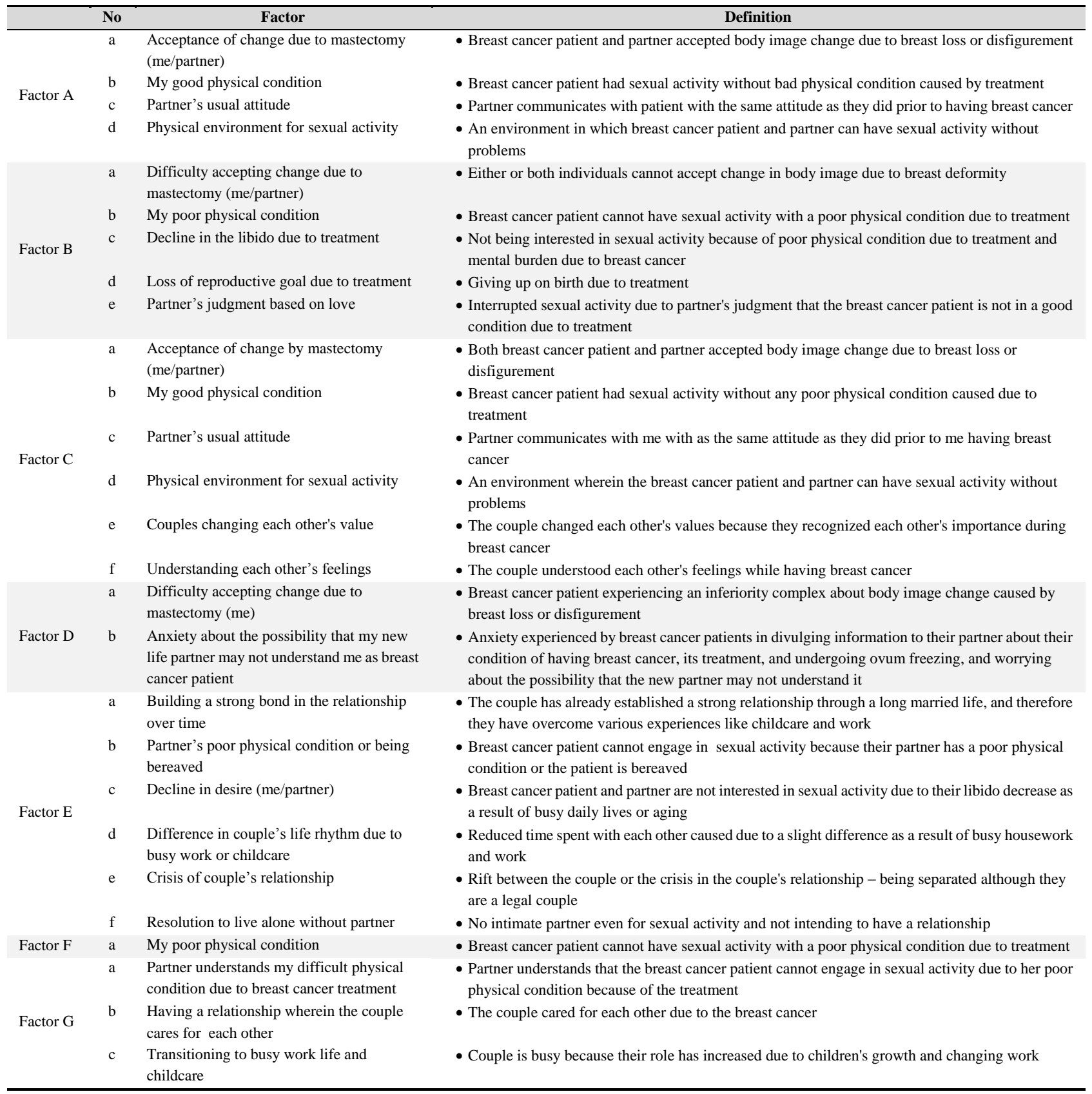

Confirming love for one another (Table 4): "Post1: No complaint" recognized that both partners were essential to each other again, and continued to confirm their affection for one another. In contrast, "Post2: Slight discord" were unable to reaffirm their love for their partner through sexual activity, and felt lonely or felt a lack of unity. Therefore, they experienced problems in their relationships and engaged in substitute behaviors such as holding hands and hugging. Moreover, some in Post 2 could not continue [2. Confirming love for one another], but instead reaffirmed their partner's love and kindness when he discontinued sexual activity for a while. "Post3: Handicapped in meeting a life partner" had become hesitant to meet new partners and begin relationships, while "Post4: Uninterested" did not feel the need for sexual activity because they were already in a strong relationship, or because they had adapted to life without it; others found it difficult and unnecessary to engage in sexual activity because they were widowed or unmarried. 
Table 4. Difference in the meaning of sexual activity in each group (Post1-Post4) during hormone therapy following

\begin{tabular}{|c|c|c|c|c|c|}
\hline \multirow{2}{*}{$\begin{array}{l}\text { Sexual activity } \\
\text { during hormone } \\
\text { therapy following } \\
\text { surgery }\end{array}$} & \multicolumn{5}{|c|}{ The meaning of sexual activity } \\
\hline & $\begin{array}{l}\text { 1. Regaining } \\
\text { femininity lost to } \\
\text { breast cancer }\end{array}$ & $\begin{array}{l}\text { 2. Confirming love for one } \\
\text { another }\end{array}$ & $\begin{array}{l}\text { 3. Sharing } \\
\text { pleasure }\end{array}$ & $\begin{array}{l}\text { 4. Response to a partner's high } \\
\text { desire }\end{array}$ & 5. Procreation \\
\hline $\begin{array}{l}\text { Post1: No complaint } \\
\text { regarding sexual } \\
\text { activity }\end{array}$ & $\begin{array}{l}\text { Regaining } \\
\text { personality }\end{array}$ & $\begin{array}{l}\text { Continuing to confirm } \\
\text { affection with partner through } \\
\text { sexual activity/Recognizing } \\
\text { that the couple is important for } \\
\text { each other }\end{array}$ & Sharing pleasure & No problem in fulfilling desire & $\begin{array}{l}\text { Considering birth with the } \\
\text { balance of treatment/ } \\
\text { Considering ovum or } \\
\text { fertilized ovum freezing/ } \\
\text { Unnecessary because of } \\
\text { not wanting baby }\end{array}$ \\
\hline $\begin{array}{l}\text { Post2: One or both } \\
\text { partners feel slight } \\
\text { discord regarding } \\
\text { sexual activity }\end{array}$ & $\begin{array}{l}\text { Feeling that she is } \\
\text { seen as a woman } \\
\text { by the partner/ } \\
\text { Unnecessary/Not } \\
\text { hing }\end{array}$ & $\begin{array}{l}\text { Feeling lonely/Feeling couple's } \\
\text { lack of unity/Experiencing } \\
\text { crisis in the relationship/ } \\
\text { Engaging in alternate } \\
\text { behaviors/Reconfirming } \\
\text { partner's kindness and love }\end{array}$ & $\begin{array}{l}\text { Impossible to } \\
\text { share } \\
\text { /Unnecessary }\end{array}$ & $\begin{array}{l}\text { Partner feeling guilty for negative } \\
\text { reactions such as grumpy attitude } \\
\text { and frustration/Feeling sorry } \\
\text { because responding to husband's } \\
\text { libido is perceived as wife's } \\
\text { role/Feeling sorry for partner for } \\
\text { being refused sexual activity/ } \\
\text { Possible to respond if partner asks } \\
\text { for sexual activity/Accepting } \\
\text { sexual activity outside marriage/ } \\
\text { Not necessary to ask for sexual } \\
\text { activity }\end{array}$ & $\begin{array}{l}\text { Considering birth with the } \\
\text { balance of treatment/ } \\
\text { Considering or undergoing } \\
\text { ovum or fertilized ovum } \\
\text { freezing/Giving up on } \\
\text { birth/Unnecessary because } \\
\text { of not wanting baby }\end{array}$ \\
\hline $\begin{array}{l}\text { Post3: Handicapped } \\
\text { in meeting a life } \\
\text { partner }\end{array}$ & $\begin{array}{l}\text { Difficulty to } \\
\text { regain femininity }\end{array}$ & $\begin{array}{l}\text { Hesitating to meet new partner } \\
\text { and developing a relationship }\end{array}$ & $\begin{array}{l}\text { Difficulty in } \\
\text { thinking about } \\
\text { sharing pleasure }\end{array}$ & $\begin{array}{l}\text { Difficulty thinking about partner's } \\
\text { desire }\end{array}$ & $\begin{array}{l}\text { Ovum freezing/ } \\
\text { Unnecessary }\end{array}$ \\
\hline $\begin{array}{l}\text { Post4: Uninterested } \\
\text { in sexual activity }\end{array}$ & $\begin{array}{l}\text { Nothing/Unneces } \\
\text { sary }\end{array}$ & $\begin{array}{l}\text { Unnecessary because of } \\
\text { already being in a relationship } \\
\text { with a strong } \\
\text { bond/Unnecessary because of } \\
\text { getting used to the situation } \\
\text { without sexual } \\
\text { activity/Difficult and } \\
\text { unnecessary because of } \\
\text { bereavement or being } \\
\text { unmarried/Nothing }\end{array}$ & $\begin{array}{l}\text { Not interested in } \\
\text { sharing pleasure } \\
\text { /Unnecessary } \\
\text { /Nothing }\end{array}$ & $\begin{array}{l}\text { Not interested in desire/ } \\
\text { Unnecessary/Nothing }\end{array}$ & $\begin{array}{l}\text { Unnecessary because of } \\
\text { not wanting a baby or } \\
\text { already having children } \\
\text { /Nothing }\end{array}$ \\
\hline
\end{tabular}

Sharing pleasure (Table 4): "Post1: No complaint" saw sexual activity as a means of sharing pleasure with their partners. "Post2: Slight discord" were not able to share pleasure with their partners through sexual activity. "Post3: Handicapped in meeting a life partner" were unable to think about sharing pleasure through sexual activity, and "Post4: Uninterested" were not interested in sharing pleasure and did not think that it was necessary.

Responding to a partner's desire (Table 4): "Post1: No complaint" satisfied their partner's desire, while "Post2: Slight discord" experienced guilt when their partners reacted negatively to their lack of desire by becoming grumpy and irritated. These women felt sorry for their partners, because they believed that dealing with their partner's desire was their duty. Some members of Post 2 thought that their partner would respond if they tried to initiate sexual activity, and some patients tolerated their partner's sexual activity with someone else. "Post3: Handicapped in meeting a life partner" were not able to think about fulfilling their partner's higher desire, and "Post4: Uninterested" did not find it necessary to do so because they did not view sexual activity as important.
Sexual activity for procreation (Table 4): While some members of "Post1: No complaint" did not want to conceive, others wanted a baby, and balanced their treatment process to achieve it (e.g., waiting before starting the treatment to try conceiving). "Post2: Slight discord" thought that sexual activity would be unnecessary unless they wanted a baby, and had adjusted the timing and nature of plans to have children to accommodate the treatment, for example by having ova frozen. Some members of Post 2 had given up hope of having children. Conversely, some in "Post3: Handicapped in meeting a life partner" had also frozen their eggs, like some in Post2. Finally, "Post4: Uninterested in sexual activity" did not want children.

\subsubsection{Strategies used to cope with changes in sexual activ- ity (see Figure 2-IV)}

Coping strategies were divided into six types (Figure 2-IV): «1. A virtuous cycle to confirm couple's love and regain lost femininity through sexual activity» (purple arrow), «2. Struggle to avoid relationship crisis related to disruption of sexual activities» (gray arrow), «3. Reconfirmation of partner's affection by his abstinence from sexual activity» (or- 
ange arrow), «4. Attempt to recover the sexual activity they hope for» (pink arrow), «5. Pursuing children or assuaging partner's desire by other means» (yellow-green arrow), and «6. Difficulty making a partner continue to have sexual activity» (light blue arrow).

Virtuous cycle to confirm couple's love and regain lost femininity through sexual activity (Figure 2-IV; purple arrow): In "Post1: No complaint," meanings of sexual activity included [1. Regaining femininity lost to breast cancer] and [2. Confirming love for one another]: interacting through sexual activity, these two created the virtuous cycle leading to [3. Sharing pleasure].

Struggle to avoid relationship crisis related to disruption of sexual activities (Figure 2-IV; gray arrow): In "Post2: Slight discord," meanings found were [2. Confirming love for one another] and [4. Response to partner's high desire]. Breast cancer patients who could not be [2. Confirming love for one another] felt $<$ Loneliness due to refusal of sexual activity $>$ and $<$ Lack of affection by one's refusal $>$; therefore, they experienced $<$ Slight differences between the couple $>$. Breast cancer patients who could not give a [4. Response to the partner's high desire] and [2. Confirming love for one another] experienced $<$ Feeling guilty for not being able to cope with partner's desire $>$, also leading to $<$ Slight differences between the couple $>$. Breast cancer patients were able to $<$ Predict crisis of couple's relationship $>$ due to the $<$ Slight differences between the couple $>$, and made $<$ An attempt to recover sexual activity they hoped for $>$ to avoid $<$ Deterioration of relationship with partner $>$, but they struggled to avoid crisis.

Some formerly satisfied participants, from "Post1: No complaint," also transitioned to Post2, by factor F, including items such as 'a. My poor physical condition'. These patients couldn't think about sexual activity as their physical condition got worse.

Reconfirmation of partner's affection by his abstinence from sexual activity (Figure 2-IV; orange arrow): In "Post2: Slight discord," meanings found included [2. Confirming love for one another] and [4. Response to the partner's high desire]. It might be natural for patients to feel guilty about being unable to respond to their partner's desire, but the patients in this group viewed a situation of no sexual activity as one of $<$ Partner's abstinence from sexual activity as partner's expression of love $>$ and $<$ Recognition of partner's love for me and being grateful for partner's patience $>$, constituting a strategy of reconfirmation of partner's affection (and mutual affection). On the other hand, some patients made an <Attempt to recover sexual activity they hope for $>$ such sleeping together to recover sexual activity before the surgery.

Attempt to recover the sexual activity they hope for (see Figure 2-IV; solid and dotted pink arrows): At first, as shown by the solid pink line, some patients who made an $<$ Attempt to recover sexual activity they hope for $>$ transitioned to "Post4: Uninterested" by factor G, which included 'a. Partner understands my difficult physical condition due to breast cancer treatment', 'b. Having a relationship wherein the couple cares for each other', and 'c. Transitioning to busy work-life and childcare.' These factors meant some patients weren't interested in sexual activity or found it less necessary. We have no solid data on this point, but we speculate that these people were attempting to recover healthy sex lives, that is, trying to achieve "Post1: No complaint" as shown by the dotted pink arrow.

Pursuing children or assuaging partner's desire by other means (Figure 2-IV; yellow-green arrow): Sexual activity for some patients in "Post2: Slight discord" was a [4. Response to the partner's high desire] or was for [5. Procreation]'; the latter also was true for patients in 'Post3: Handicapped meeting a life partner".

Some of the patients showed $<$ Acceptance of outside sexual relations $>$ in [4. Response to the partner's high desire]. In addition, some of them felt $<$ Difficulty giving up on having a baby $>$ or the need to <Giving hope to their parents about grandchildren $>$, under [5. Procreation]; therefore, they froze ova to allow them to be implanted later.

Difficulty making a partner continue to have sexual activity (see Figure 2-IV; light blue arrow): Breast cancer patients in "Post3: Handicapped meeting a life partner" did not adhere to any of the meanings of sexual activity except for [5. Procreation], because they had difficulty maintaining a relationship with a life partner, and instead were moving from situation to situation transiently.

\section{Discussion}

\subsection{The characteristics of sexual life before diagnosis}

The sexual life of breast cancer patients before diagnosis was divided into four groups: satisfied, discordant, searching, and uninterested.

A factor in the sexual lives of even healthy Japanese couples, compared to couples from other cultures, is the tendency to not engage in sexual activity. ${ }^{[28]}$ We believe that this tendency is influenced not only by the Japanese culture, which promotes avoidance and shame toward sexual activity, but also by contemporary lifestyles. Our research showed that many participants did not consider their sexual lives to be important prior to having breast cancer, and so many of them 
were already in a situation of not engaging in sexual activity often. The reasons included being too busy with work, the demands of motherhood, housework, and physical changes (such as menopause, declining libido, and becoming easily fatigued) caused by aging. Therefore, we concluded that our sample had similar reasons for not engaging in sexual activity as the women in the wider population.

\subsection{Sexual life during post-surgical hormone therapy}

Breast cancer patients' sexual lives during hormone therapy were divided into four groups: "Post1: No complaint regarding sexual activity", "Post2: One or both partners feel slight discord regarding sexual activity", "Post3: Handicapped in meeting a life partner" and "Post4: Uninterested in sexual activity". These demonstrated that the sexual lives of participants did not change significantly after breast cancer.

Upon comparing the experiences of each group before and after cancer, it was found that many patients remained in the same situation; however, some patients transitioned into different groups over time. Factors determining the direction of this movement were identified (A-E in Figure 2). As was revealed, the sexual lives of patients did not change significantly over the course of the illness, with $35.1 \%$ of our sample considering sex to be uninteresting prior to their diagnosis. In a general survey of 16-49-year-old men and women, Kitamura found that the celibate population was increasing in Japan. ${ }^{[28]}$

\subsubsection{Factors resulting in changes to sexual life}

For the majority of the participants $(n=29)$, breast cancer did not lead to any significant changes in their sexual lives. One novel point this research revealed is the combination of factors that determine the direction of change in sexual life during hormone therapy following surgery in the Japanese breast cancer patient population. We believe that attending to these influencing factors will be useful in informing screening measures used to identify individuals who consider their sexual lives to be important.

The factors (A-E) influencing the sexual lives of patients were divided into two types: factors that were influenced by breast cancer and those that were not. The former (Figure 2) included factors related to breast cancer treatment: physical condition caused by breast cancer treatment, as in factor A-b: 'My good physical condition', factor B-b: 'My poor physical condition' and factor C-b: 'My good physical condition'; change in body image, as in factor A-a: 'Acceptance of change due to mastectomy (me/partner)', factor B-a: 'Difficulty accepting change due to mastectomy (me/partner)', factor C-a: 'Acceptance of change by mastectomy (me/partner)', and factor D-a: 'Difficulty accepting change due to mastec- tomy (me)'; decline in desire, as in factor B-c: 'Decline in desire due to treatment'; difficulty in giving birth, as in factor B-d: 'Loss of reproductive goal due to treatment'; partner's attitude toward the patient, as in factor C-c: 'Partner's usual attitude', and anxiety that new partners would not be able to understand the effects of breast cancer treatment, as in factor D-b: 'Anxiety about the possibility that my new partner may not understand me as a breast cancer patient.' The factors not influenced by breast cancer included being busy with child care and work, as in factor E-d: 'Difference in couple's life rhythm due to busy work or childcare'; partner's poor physical condition or patient's being widowed, as in factor E-b: 'Partner's poor physical condition or being bereaved'; decline in desire with age, as in factor E-c: 'Decline in desire (me/partner)'; feeling that sexual activity was not needed to maintain a relationship with one's partner, as in factor E-a: 'Building a strong bond in the relationship over time', and factor E-e: 'Crisis of couple's relationship'; and resolution to live alone without a partner, as in factor E-f: 'Resolution to live alone without partner' - the last one characteristic of the context, as the rate of the unmarried is increasing in Japan.

On this basis, factors influencing sexual activity after breast cancer could be grouped more broadly into two types: related to breast cancer or not. These different types of factors need different types of support from nurses. Their nature and the nature of this support is considered further below.

\subsubsection{Changes in sexual life during hormone therapy fol- lowing surgery}

Change in sexual life during hormone therapy included the following: transition from "Pre1: Satisfactory sexual activity" to "Post1: No complaint" and to "Post2: Slight discord," from "Pre2: Slight discord" to Post1 and Post2, from "Pre3: Searching for life partner" to "Post3: Handicapped in meeting a life partner," and from "Pre4: Uninterested in sexual activity" to "Post4: Uninterested in sexual activity." Three of these transitions are likely to need support from health personnel: the ones from Satisfactory sexual activity" to "Discord" (Pre1 to Post2), from "Discord" to "Discord," (Pre2 to Post2), and from "Searching for a life partner" to "Handicapped in meeting a life partner" (Pre3 to Post3).

The transitions from Pre1 and Pre2 to Post2, that is, from satisfaction or discord to discord, were influenced by Factor B, which has five components. First is 'B-a: Difficulty accepting change due to mastectomy (me/partner)', which is also a characteristic problem for breast cancer patients in previous studies. ${ }^{[29]}$ Effective support, in particular counseling support, is necessary for patients and partners to accept the breast loss or disfigurement. Next, 'B-b: My poor physi- 
cal condition' and 'B-c: Decline in desire due to treatment' require attention from caregivers to reducing deterioration of patients' physical condition and supporting them in coming to grips with the physical changes their body has undergone. 'B-d: Loss of reproductive goal due to treatment', can be addressed by nurses through provision of information on ovum freezing. 'B-e: Partner's judgment based on love' indicated that the partners decided to suspend sexual activity based on the patient's poor physical condition. We consider it important for partners to support breast cancer patients and understand their poor physical condition and body image changes.

Second, patients who move from "Pre3: Searching for a life partner" to "Post3: Handicapped in meeting a life partner" need support to maintain healthy sex lives. This transition is influenced by factor $\mathrm{D}$, which has two components: ' $\mathrm{D}-\mathrm{a}$ : Difficulty accepting change due to mastectomy (me)' indicates that nurses need to support patients to accept breast loss or disfigurement, as in factor B-a, while. 'D-b: Anxiety about the possibility that my new life partner may not understand me as a breast cancer patient' indicates the patient's anxiety about future partners' response to their breast cancer. This factor implies that nurses need to support patients to recover their self-esteem, and also that education activities for people who have not been exposed to breast cancer are important for their understanding.

Third, the transition from Pre2 to Post1, that is, from discord to no complaint, may have occurred at least in part because patients and partners recognized each other's importance in their lives after facing the possibility of the death of the patient due to breast cancer.

Fourth, many factors related to the transition from uninterested to uninterested (Pre4-Post4), such as being busy with work and childcare, are related to sexlessness. We considered these factors to be unrelated to breast cancer. They are similar to those identified in a general population by Moriki. ${ }^{[30]}$ Nurses can screen patients in this group using factor $\mathrm{E}$, which has five components. 'E-a: Building a strong bond in the relationship over time' and 'E-e: Crisis of couple's relationship' cause patients to think sexual activity unnecessary because the couple's relationship is so strong bond or, conversely, because it has already been broken, for example if the partners have separated. 'E-b: Partner's poor physical condition or being bereaved' covers cases where the participant's physical condition makes sexual activity difficult-if one partner suffers from the disease, to some degree both do, and the priority of sexual activity decreases as the couple seeks to support each other. Third, 'E-f; Resolution to live alone without partner' covers patients who feel they don't need a life partner at the present stage - an increasingly common scenario in Japan. ${ }^{[31]}$

It is important for patients to receive support in relation to all these life challenges to help them recover. Assessments to evaluate both cancer-related and non-cancer-related factors can help health personnel support patients and aid them in retaining or achieving sex lives that are of value to them.

\subsubsection{Meanings of sexual activity and their characteristics}

Five meanings of sexual activity were identified (Regaining femininity, Confirming love with one another, Sharing pleasure, Responding to the partner's high desire, Procreation). Taken together, these meanings yield a concept of sexuality similar to that provided by the WHO: ${ }^{[2]}$ "Sexuality is a central aspect of being human throughout life and encompasses sex, gender identities and roles, sexual orientation, eroticism, pleasure, intimacy, and reproduction". ${ }^{[2]}$ Cancer patients' search for a meaningful life and a way to live their values changes after their illness and their increased sense of their own mortality. ${ }^{[32]}$ However, the meaning of sexual activity in this study was not found to change greatly, and so we consider that sexual life for breast cancer patients in Japan may be associated with perceptions and preferences in the context of their lives as a whole.

Two findings of particular importance were as follows. First, regarding lost femininity: the meaning of sexual activity as a way of expressing one's femininity is also reflected in the WHO definition, and therefore is shared with healthy women; however, it may take on even more importance in breast cancer patients as a way of regaining femininity lost due to cancer. Second, responding to partner's high libido is also reflected in the WHO definition; however, the perception of one's partner's desire as particularly strong may be related to one's own lower desire as a result of breast cancer and treatment. Part of support for breast cancer patients will be understanding the reasons for this declining desire in detail.

\subsection{Characteristics of coping processes \\ 4.3.1 Effect of meaning of sexual activity as perceived by patients}

Coping with changes in sexual activity was different from patient to patient according to the meaning they attached to sexual activity. Coping was divided into two types based on whether coping mechanisms were sexual only or also non-sexual. For example, responding to a partner's high libido and procreation desires may be accomplished through methods that do not involve the patient's sexuality, such as allowing the partner to have sex with others or expecting the partner to masturbate instead of engaging in sexual activity. Similarly, for reproduction, breast cancer patients can select medical technologies such as ovum freezing.

ISSN 2324-7940 E-ISSN 2324-7959 
On the other hand, many breast cancer patients require sexual activity to regain femininity and/or confirm love within their relationships. If it is difficult for them to do so due to their poor physical condition, it is important to promote other loving activities such as holding hands and sleeping in the same bed. It's said the importance of expressing affection in way other than sexual activity. ${ }^{[16]}$ Nurses must understand the difference between these two types of coping methods and how they are influenced by the meaning attached to sexual activity, and must understand the particular patient's feelings in this regard to help them settle on coping strategies for their own unique sexual lives.

\subsubsection{Difficulties with the available solutions}

In Figure 2-IV, coping strategies were classified into six types, differentiated by the meaning attached to sexual activity. The gray arrow predicted relationship crisis caused by discord over sexual activity. The orange arrow showed the case where the patient's physical condition led to the decision to stop sexual activity, which was generally appreciated by the patient and viewed as a token of the partner's love. This result was distinct from the results of previous studies in other national contexts, which showed that sexlessness correlated with worse couple relationships. ${ }^{[33]}$ The patients who followed the gray and orange arrows thought sexual activity was necessary. Although not clear in this study, they will follow the process indicated in the pink dotted arrow in Figure 2, which aims for "Post1: No complaint regarding sexual activity." Nurses need to provide these patients with information on methods such as hugging or going to bed together instead of sexual activity.

The average term after surgery of study participants was about a year and a half, and the longest term was 4 years and 5 months. Despite these long terms, our study length did not permit obtaining data on the process shown by the pink arrow, that is, reaching "Post1: No complaint." This seems to show that it is difficult for the patients to resume sexual activity after sexlessness, and it takes a lot of time to solve sexual problems. Moreover, in Japan, the general tendency toward non-sexual couple relationships is strong. ${ }^{28]}$ Thus, breast cancer patients may be particularly likely to postpone dealing with sexual issues, as they may not tend to prioritize them or view sex as an important part of their daily life. Nurses can support this process by helping patients reduce their physical burden, accept breast loss or disfigurement, and talk candidly about sexual activity.

Breast cancer patients enrolled in hormone therapy can lead normal daily lives, unlike chemotherapy and radiation therapy patients, meaning that these patients have more opportunity to think about and cultivate their sexual lives. However,

Published by Sciedu Press sexual problems continue to be ignored by these patients, as they are difficult to solve. Moreover, medical staff often do not find it necessary to support breast cancer patients during hormone therapy because they can spend their daily life without support. Given this lack of support, sexual problems might worsen. The survival rate of breast cancer is high; therefore, many breast cancer patients lead long, normal lives after treatment. Continuing sexual problems can cause their QoL to decline, ${ }^{[34]}$ and medical staff may be at risk of disregarding these issues as not directly related to their condition, treatment, and recovery. Thus, medical staff should be encouraged and educated to carefully assess sexual life problems.

Nurses can offer two main types of support in this regard. First, they should ensure that they understand the meaning of sexual life for their patients, and support patients in selecting appropriate methods of coping. Secondly, nurses need to understand the factors that lead to sexual difficulties and support their patients to overcome these issues and achieve a satisfactory sexual life. In Japan, the cultural and social background may make it even more difficult to solve sexual problems. However, this research shows that such support is necessary from the beginning of treatment and is required for the duration of treatment.

\subsection{Limitations}

This research has certain limitations that should be acknowledged. First, it does not assess the long-term experiences of patients, as our participants had been receiving hormone therapy for less than 5 years. Therefore, both longitudinal research and research with greater variation in time since diagnosis are required. Second, all our participants were females, which may not present a complete picture. As sexual life involves both the individuals in a couple, partners of patients should be included in future research.

\section{Conclusions}

(1) Patients' sexual lives were divided into 4 groups. Most patients' sexual lives didn't change from before breast cancer to during surgical-hormonal therapy (they remained in the same group). We think this is because, given that cancer is a life-threatening disease, sex took on a low priority.

(2) Patients who experienced marital discord around sexual activity and those who could not find partners after their treatment need support to attain healthy sexual lives after cancer. The meanings of sexuality, factors affecting it, components of those factors, and coping strategies identified here should all be considered in designing supportive interventions. At the same time, 
in general, these interventions should keep in mind the private and sometimes sensitive nature of sexuality, and be implemented delicately. Also, nurses should screen for patients who think sexual activity is unnecessary, by paying attention to factor $\mathrm{E}$.

(3) The meanings patients attached to sexual activity were of five types: [1. Regaining femininity lost to breast cancer], [2. Confirming love for one another], [3. Sharing pleasure], [4. Response to a partner's high desire], [5. Procreation]. These meanings were similar to those identified by the WHO, but there were differences in two: [1. Regaining femininity lost to breast cancer] and [4. Response to a partner's higher desire].

(4) At first, in [1. Regaining femininity lost to breast cancer], it was more important for the patients because they lost their breasts due to surgery. Secondly, in [4. Response to a partner's high desire], patients felt their partner's unchanged desire as a burden because of their poor physical condition due to treatment, and often discontinued sexual activity. Previous studies have shown that patients worried about relationship crisis because they could not respond to their partner's desire. However, in Japan, the partners accepted those who could not have sexual activity and the patients regarded discontinuation of sexual activity as a sign of their partner's affection, therefore, the relationships did not grow worse.

(5) The patients could achieve: [1. Regaining femininity lost to breast cancer], [2. Confirming love for one another] and [3. Sharing pleasure] through sexual activity, and [4. Response to a partner's high desire] and [5. Procreation] by alternative methods.

(6) It was found that discord around sexual activity predicted relationship crisis and that it was a difficult and lengthy process for patients to resume sexual activity. Nurses should give patients information about alternatives to sexual activity as well as intervene to help patients resume sexual activity.

(7) As hormone therapy has fewer side effects than other treatments, it had less effect on patients' sexual lives. However, this also led to sexual problems being ignored and having the chance to worsen. Nurses should be particularly careful not to miss sexual problems in these patients.

\section{CONFlicts OF INTEREST Disclosure}

The authors declare they have no conflicts of interest.

\section{REFERENCES}

[1] Hordern A. Intimacy and sexuality for the woman with breast cancer. Cancer Nurs. 2000; 23(3): 230-236. PMid: 10851774. https://doi.org/10.1097/00002820-200006000-00011

[2] World Health Organization. Defining sexual health. Cited 2017 Jan 15. Available from: http://www. who.int/reproductiveheal th/topics/sexual_health/sh_definitions/en/

[3] Woloski-Wruble AC, Dekeyzer Ganzs F, Jiang Y, et al. Israeli and Chinese partners of women with breast cancer: a cross-cultural view of marital issues. Psychooncology. 2012; 21(3): 324-331. PMid: 22383274. https://doi.org/10.1002/pon.1899

[4] Hill EK, Sandbo S, Abramsohn E, et al. Assessing gynecologic and breast cancer survivors' sexual health care needs. Cancer. 2011; 117(12): 2643-2651. PMid: 21656742. https://doi.org/10.1 $002 / \mathrm{cncr} .25832$

[5] International Agency for Research on Cancer, Estimated number of incident cases, females, worldwide (top 10 cancer sites) in 2012. Cited 2017 Jan 15. Available from: http://gco.iarc.fr/today/ online-analysis-multi-bars?mode=cancer\&mode_poppop ulat =continents\&population $=900 \&$ se $x=2 \&$ cancer $=29 \& t y p$ $\mathrm{e}=0$ \&statistst $=0$ \&prevalence $=0 \&$ color_palette $=$ def ault

[6] Takahashi M, Kai I. Sexuality after breast cancer treatment: changes and coping strategies among Japanese survivors. Soc Sci Med. 2005; 61: 278-1290. PMid: 15970237. https://doi.org/10.1016/j . socscimed.2005.01.013

[7] Lorraine A, Sheppard B, Ely SB. Breast cancer and sexuality. Breast J. 2008; 14(2): 176-181. PMid: 18248559. https://doi.org/10 $.1111 / \mathrm{j} .1524-4741.2007 .00550 \cdot \mathrm{x}$
[8] Kokufu H, Inoue T. Syuzyuturyouhou wo ukeru nyuugankanzya no zyutusikisentaku no purosesu ni kansuru kenkyuu [The process of decision-making regarding surgical treatment by breast cancer patients]. J Jpn Acad Nurs Sci. 2012; 22(3): 20-28. https: //doi.org/10.5630/jans1981.22.3_20

[9] Dizon DS. Quality of life after breast cancer: survivorship and sexuality. Breast J. 2009; 15: 500-504. PMid: 19614908. https: //doi.org/10.1111/j.1524-4741.2009.00766.x

[10] Thewes B, Meiser B, Rickard J, et al. The fertility-and menopauserelated information needs of younger women with a diagnosis of breast cancer: a qualitative study. Psychooncology. 2003; 12: 500511. PMid: 12833562. https://doi.org/10.1002/pon.685

[11] Tokunaga E, Hisamatsu Y, Tanaka K, et al. Molecular mechanisms regulating the hormone sensitivity of breast cancer. Cancer Sci. 2014; 105(11): 1377-1383. PMid: 25155268. https://doi.org/10.1 $111 /$ cas .12521

[12] Davies C, Pan H, Godwin J, et al. Adjuvant Tamoxifen: Longer Against Shorter (ATLAS) Collaborative Group. Long-term effects of continuing adjuvant tamoxifen to 10 years versus stopping at 5 years after diagnosis of oestrogen receptor-positive breast cancer: ATLAS, a randomised trial. Lancet. 2013; 381: 805-816. https://doi.org/10.1016/S0140-6736(12)61963-1

[13] Ganz PA, Desmond KA, Belin TR, et al. Predictors of sexual health in women after a breast cancer diagnosis. J Clin Oncol. 1999; 17(8): 2371-2380. PMid: 10561299. https://doi.org/10.1200/JCO. 1999.17.8.2371

[14] Sena Y, Keiko T, Mitsuyo N, et al. Horumon ryouhou wo kaishi suru nyuugan kanzya ga chiryoukaishisouki ni taikensuru kounenkisy- 
ouzyou to QOL no henka [Changes in menopausal symptoms and quality of life in women with breast cancer in early phase of hormonal therapy]. J Jpn Soc Cancer Nurs. 2015; 29(2): 25-32.

[15] Ganz PA, Rowland JH, Desmond K, et al. Life After breast cancer: Understanding women's health-related quality of life and sexual functioning. J Clin Oncol. 1998; 16(2): 501-514. PMid: 9469334. https://doi.org/10.1200/JC0.1998.16.2.501

[16] Holmberg SK, Scott LL, Alexy WL, et al. Relationship issues of women with breast cancer. Cancer Nurs. 2001; 24(1): 53-60. PMid: 11219423. https://doi.org/10.1097/00002820-200102000 $-00009$

[17] Ussher JM, Perz J, Gilbert E. Changes to sexual well-being and intimacy after breast cancer. Cancer Nurs. 2012; 35(6): 456-465. PMid: 22222680. https://doi.org/10.1097/NCC.0b013e31 82395401

[18] Beckjord E, Compas BE. Sexual quality of life in women with newly diagnosed breast cancer. J Psychosoc Oncol. 2007; 25(2): 19-36. PMid: 17613483. https://doi.org/10.1300/J077v25n02_02

[19] Fang SY, Lin YC, Chen TC, et al. Impact of material coping on the relationship between body image and sexuality among breast cancer survivors. Support Care Cancer. 2015; 23(9): 2551-2559. PMid: 25617071. https://doi.org/10.1007/s00520-015-2612-1

[20] Ussher JM, Perz J, Gilbert E. Information needs associated with changers to sexual well-being after breast cancer. J Adv Nurs. 2012; 17: 327-337.

[21] Male DA, Fergue KD, Cullen K. Sexual identity after cancer: sexuality, body, and relationship repercussions. Curr Opin Support Palliat Care. 2016; 10(1): 66-74. PMid: 26716393. https://doi .org/10 $.1097 /$ SPC .0000000000000184

[22] Miki Y, Hohashi N, Maekawa A. Wagakuni no hokeniryouryouikini okeru sekusyuariteli no gainenbunseki [A concept analysis of sexuality in Japan's health and medical care domain]. J Jpn Acad Nurs Sci. 2013; 33(2): 70-79. https://doi.org/10.5630/jans.33.2_70

[23] Jun EY, Kim S, Chang SB, et al. The effect of a sexual life reframing program on marital intimacy, body image, and sexual function among breast cancer survivors. Cancer Nurs. 2011; 34(2): 142149. PMid: 20885305. https://doi.org/10.1097/NCC.0b013e $3181 \mathrm{f} 1 \mathrm{ab} 7 \mathrm{a}$

[24] Gabalici E, Terzioglu F. The effect of family planning methods used by women of reproductive age on their sexual life. Sex Disabil. 2010; 28: 275-285. https://doi .org/10.1007/s11195-0 10-9161-9
[25] Corbin J, Strauss M. Shitsutekikenkyuu no kiso guraundeddo seori kaihatsu no gihou to tezyun (dai 3 han) [Basics of Qualitative Research Techniques and Procedures for Developing Grounded Theory (3rd Edition)]. Translated by Hanako M, Takashi M. Tokyo: IgakuShoin; 2014.

[26] Saiki Craighill S. Shitsuteki kenkyuhou zeminaaru guraundeddo seorii apuroochi wo manabu (dai 2 han) [Qualitative research seminar learning grounded theory approach (2nd Edition)]. Tokyo: IgakuShoin; 2015.

[27] Kondo M. Shi wo mitori tudukeru kangosi no hitankatei: inochi nisyoumen kara mukiaukoto ni yotte motarasareru kunou heno taiou [Grieving process of nurses continuing to care for dying patients: dealing with distress resulting from facing life and death directly]. Tokyo; Kazamashobo; 2011.

[28] Japan Family Planning Association. Dai nana kai danzyo no seikatu to ishiki ni kansuru cyousa [The 7th survey on the lives and consciousness of women and men]. Cited 2017 Oct 15. Available from: http://www.jfpa.or.jp/paper/main/000047.html\#1

[29] Andrzejczak E, Markocka-Maczka K, Lewandowski A. Partner relationships after mastectomy in women not offered breast reconstruction. Psychooncology. 2013; 22(7): 1653-1657. PMid: 23045167. https://doi.org/10.1002/pon.3197

[30] Moriki Y, Matsukura R. Sekkusuresu huuhu no haikei syakai: bunkateki haikei ni cyuumokushite [The background of the sexless couple: Focusing on society and cultural background]. Jpn J Impot Res. 2003; 24(2): 204-205

[31] Ministry of Internal Affairs and Communications (Japan) National census. Cited 2017 October 18. Available from: http://www.stat.go.jp/data/kokusei/2015/kekka/kih on1/pdf/gaiyou1.pdf

[32] Garland SN, Stainken C, Ahluwalia K, et al. Cancer-related search for meaning increases willingness to participate in Mindfulness-Based Stress Reduction. Integr Cancer Ther. 2015; 14(3): 231-239. PMid: 25870034. https://doi.org/10.1177/1534735415580682

[33] Andresen BL, Carpenter KM, Yang HC, et al. Sexual well-being among partnered women with breast cancer recurrence. J Clin Oncol. 2007; 25(21): 3151-3157. PMid: 17634495. https ://doi .org/10 $.1200 /$ JC0. 2006.09.6958

[34] Ganz PA, Coscarelli A, Fred C, et al. Breast cancer survivors: psychosocial concerns and quality of life. Breast Cancer Res Treat. 1996; 38: 183-199. PMid: 8861837. https://doi.org/10.1007/BF01 806673 